\title{
Live High-Train Low Altitude Training: Responders and Non- Responders
}

Hamlin $\mathbf{M} \mathbf{J}^{1^{*}}$, Manimmanakorn $\mathbf{A}^{1,2}$, Creasy $\mathbf{R H}^{3}$ and Manimmanakorn $\mathbf{N}^{1,4}$

\begin{abstract}
Objective: Investigate differences between athletes that responded (improved performance) compared to those that did not, after a 20day "live high-train low" (LHTL) altitude training camp.

Methods: Ten elite triathletes completed 20 days of live high $(1545-1650 \mathrm{~m})$, train low $(300 \mathrm{~m})$ training. The athletes underwent (i), two 800-m swimming time trials at sea-level (1 week prior to and 1 week after the altitude camp) and (ii) two 10-min standardised submaximal cycling tests at altitude on day 1 and day 20 of the altitude camp. Acute mountain sickness (AMS) was also measured during the camp. Based on their $800-\mathrm{m}$ swimming time trial performances, athletes were divided into responders (improved by $3.2 \pm 2.2 \%$, mean $\pm S D, n=6$ ) and non-responders (decreased by $1.8 \pm 1.2 \%, n=4)$.
\end{abstract}

Results: Compared to non-responders, the responders had lower exercise heart rates $(-6.3 \pm 7.8 \%$, mean $\pm 90 \% \mathrm{CL}$, and higher oxygen saturations $(1.2 \pm 1.3 \%)$ at the end of the 10 -min submaximal test after the camp. Compared to the responders, the non-responders had substantially higher VE and VE/ $\mathrm{VO}_{2}$ during the submaximal test on day 1 of the altitude training camp, and a substantially higher RER during the submaximal test on day 20 of the camp. As a result of the altitude training, exercise economy of the non-responders compared to the responders deteriorated (i.e., non-responders required more oxygen per watt). Non-responders were 3.0 times $(90 \% \mathrm{CL}=0.5-16.6)$ more likely to suffer symptoms of acute mountain sickness during first 5 days of altitude compared to responders.

Conclusion: Changes in $\mathrm{SpO}_{2}$, heart rate and some respiratory variables during exercise and resting AMS scores may help determine athletes that respond to LHTL altitude training camps from athletes that fail to respond to such training.

Keywords: Oxygen saturation; Acute mountain sickness; Submaximal exercise; Altitude training; Triathlon; Elite athletes

\section{Introduction}

The LHTL protocol (live at high altitude and train at or near sea level) has been shown to be the most effective altitude training method for improving sea level performance among athletes $[1,2]$ and remains a very popular training method for elite athletes [3]. One of the key issues in the final outcome of LHTL altitude training is the problem of 'non-responders'. Some athletes thrive on altitude

*Corresponding author: Michael John Hamlin, Department of Tourism, Sport and Society, Lincoln University, Christchurch 7647, New Zealand, Tel: +64-3423-0489; Fax: +64-3-325-3857; E-mail: mike.hamlin@lincoln.ac.nz

Received: February 24, 2015 Accepted: May 20, 2015 Published: May 26, 2015 training and their performance improves, while others either fail to improve or suffer performance decline. It is currently not known why some athletes 'respond' to altitude and why others do not.

Many researchers have investigated the individual variability in athletes' response to altitude training. Investigators have suggested that some athletes experience a better haematological response at altitude than others [4-6], which may help reduce stress by allowing more oxygen to be transported to the working muscle. Chapman et al. found that performance improvement was associated with increased Erythropoietin (Epo) which increased total red cell volume and subsequently $\mathrm{VO}_{2 \max }$ after a 28 -day altitude training camp in responders [5]. However, wide inter-individual variability has been found in erythropoietic response to altitude training which might not identify those elite athletes who respond to altitude training [7]. For example, Ge et al. reported individual responses in Epo ranged from -41 to $400 \%$ from baseline after 24 hours at $2800 \mathrm{~m}$ [8].

Recently researchers have searched for genetic determinants of the individual variability of the Epo response to altitude which may help explain why some athletes respond and some do not. While some researchers have identified specific genes associated with successful human existence at high altitude [9], others have reported little association between the proposed genes involved in Epo regulation and Epo response to hypoxia [10]. In addition, Hypoxia Inducible Factor (HIF-1) gene expression quantification after a 3-h hypoxia test performed before training was unable to predict poor and good responder athletes to the living high-training low model [11]. Others have suggested that individual difference in the tolerance to hypoxia may be explained by an increased Acute Mountain Sickness (AMS) incidence [12], which subsequently affects training and adaptation and ultimately performance. In short, the differentiation between responders and non-responders is probably based on many factors including genetic predisposition [13], automatic nervous system adaptation [14], hypoxia-induced ventilator drive [15], underlying individual fitness levels, fatigue recovery and motivation [16]. It is clear that there is considerable individual variation in the physiological responses of athletes using altitude training, which makes the prediction of responders and non-responders very difficult. Some researchers have recently suggested screening individuals prior to altitude training may help identify those that may be negatively affected by such training [6], however pre-altitude testing is not always possible particularly on national squads that are commonly dispersed around the world.

The aim of the current project was to investigate different physiological (i.e., oxygen saturation, oxygen consumption, heart rate and performance responses) and subjective (acute mountain sickness (AMS), rate of perceived exertion (RPE)) responses of athletes undergoing training at a 20-day altitude camp in the hope of identifying possible parameters that may help identify responders from non-responders.

\section{Methodology}

\section{Altitude}

When deciding on an altitude to conduct a live-high train-low 
model of training it is important to consider the effects of using an altitude that is high enough to produce a positive physiological response, but not so high as to reduce the recovery from training or cause unwanted clinical effects (nausea, dehydration etc.). A number of studies have suggested an altitude between 2000 and $2500 \mathrm{~m}$ is ideal for live-high train-low training, based mainly on the haematological response [8,17]. However recent research suggests athletes can improve performance after altitude training without positive haematological adaptation [18]. Therefore basing the altitude training threshold purely on haematological changes is probably unwise $[19,20]$. The altitude of $1545-1650 \mathrm{~m}$ used in this study was based mainly on practical reasons (a convenient ski lodge with all the necessary essentials was available at this altitude), but was also backed by contemporary research. Low to moderate altitude has previously been shown to produce significant improvements in sea level swim time trial performance $(\sim 1.9 \%)$ [21]. Indeed, in a recent study proclaiming the use of altitudes between $2000-2500 \mathrm{~m}$ the authors also found positive physiological (red cell mass volume $\sim 7 \%, \mathrm{VO}_{2} \sim 2 \%$ ) and performance $(\sim 1 \%)$ effects for athletes on immediate return to sea level after living at $1754 \mathrm{~m}$ [17]; something that is not uncommon at these low altitudes $(1200 \mathrm{~m})$ [22]. Performance improvements of this magnitude would indicate meaningful effects for the very elite triathletes involved in this study [23].

\section{Subjects}

Ten elite triathletes were recruited from the New Zealand Academy of Sport development programme. All of the subjects (6 males and 4 females) who participated in the present study were international level athletes. The research was conducted over the summer period at Snow Farm (1545-1650 m), Wanaka, New Zealand. The study was approved by the Lincoln University Human Ethics Committee. Informed, voluntary, written consent was obtained from each subject prior to the start of the study. All subjects were free from injury, lived at sea level and had not been residents at altitude within the past 6 months. Subject characteristics and baseline measures of training are presented in Table 1.

\section{Study design}

The elite triathletes slept and stayed at the Snow Farm (1545$1650 \mathrm{~m})$ and travelled to train at Wanaka $(300 \mathrm{~m})$ for approximately $2.7 \pm 1.2$ hour/day for 20 days during the camp. All subjects performed two exercise tests; swimming and submaximal cycling on day 1 and day 20 of the training camp. During the altitude camp, five subjects were randomly selected to receive iron supplementation of 1 capsule a day (controlled release iron tablets containing dried Ferrous Sulphate

Table 1: Characteristics and training workloads of athletes in the two training groups.

\begin{tabular}{|c|c|c|}
\hline Variables & $\begin{array}{l}\text { Responders } \\
\quad(n=6)\end{array}$ & $\begin{array}{c}\text { Non-responders } \\
(n=4)\end{array}$ \\
\hline Age $(y)$ & $23.5 \pm 4.2$ & $21.0 \pm 2.0$ \\
\hline Body mass $(\mathrm{kg})$ & $64.7 \pm 7.4$ & $66.1 \pm 7.4$ \\
\hline Height $(\mathrm{cm})$ & $173.2 \pm 6.4$ & $175.2 \pm 5.1$ \\
\hline Gender & Male 3; Female 3 & Male 3; Female 1 \\
\hline $\mathrm{BMI}\left(\mathrm{kg} \cdot \mathrm{m}^{-2}\right)$ & $21.8 \pm 1.3$ & $21.8 \pm 3.1$ \\
\hline Swim Training (Trimp. $d^{-1}$ ) & $163.7 \pm 69.5$ & $161.7 \pm 68.3$ \\
\hline Bike Training (Trimp.d ${ }^{-1}$ ) & $218.3 \pm 127.3$ & $184.3 \pm 84.8$ \\
\hline Run Training (Trimp.d ${ }^{-1}$ ) & $137.1 \pm 96.1$ & $113.9 \pm 73.4$ \\
\hline Total Training (Trimp. $\mathrm{d}^{-1}$ ) & $519.0 \pm 41.4$ & $459.8 \pm 35.9$ \\
\hline
\end{tabular}

Note: Data are mean \pm SD. No substantial difference between groups.
BP $325 \mathrm{mg}$ (equivalent to $105 \mathrm{mg}$ element iron), vitamin C $500 \mathrm{mg}$ as sodium ascorbate (FERROGRAD C, Abbott Laboratories (NZ) Ltd, Naenae)), while five subjects received a placebo. No contraindications for iron supplementation were found in any participants prior to the training camp, with all subjects showing normal iron, haemoglobin and ferritin levels $\left(19.6 \pm 4.4\right.$ umol.L ${ }^{-1}, 145.0$ g. $\mathrm{L}^{-1} \pm 7.8,82.9 \pm$ 30.9 ug. $\mathrm{L}^{-1}$ mean \pm SD for serum iron, haemoglobin and ferritin respectively). Retrospectively, based on their $800-\mathrm{m}$ swim time trial, athletes were divided into responders $(n=6)$ who had positive results (decreased their swimming time) and non-responders ( $\mathrm{n}=4$ ) who had negative results (increased their swimming time).

\section{Testing}

Maximal exercise test: Performance was assessed by individual 800-m timed swim trials in a standard $25-\mathrm{m}$ pool near sea level. Time trials were performed at the same time each day with similar water temperature and brands of swimming costumes. Subjects completed a standardised 10-15 min warm-up with stretching prior to the swim. Subjects were instructed to try to achieve the best time possible during the swim, but were not provided with feedback on time or pace.

Submaximal exercise test: The submaximal cycling test was performed at altitude on each athlete's own bicycle set up on a stationary ergometer (Cycle Ops Fluid 2, Madison, WI, USA) at the same time of day, on the first and last day of the altitude camp. Subjects performed the 10-min submaximal test at $250 \mathrm{~W}$ (for males) or $200 \mathrm{~W}$ (for females) during which heart rate (S610; Polar, Kempele, Finland), oxygen saturation (Sport-Stat, Nonin Medical, Minneapolis, MN) and rate of perceived exertion were recorded every minute. In addition, ventilation and expired gases were measured breath-by-breath using a portable gas exchange system (MetaMax ${ }^{\circledR}$ 3B; Cortex Biophysik, Leipzig, Germany). Before testing, the gas analyser was calibrated for volume (Hans Rudolph 55303 L syringe; Kansas City, MO, USA) and gas composition $\left(15 \% \mathrm{O}_{2}\right.$ and $\left.5 \% \mathrm{CO}_{2}\right)$. Oxygen consumption ( $\dot{\mathrm{V}}$ $\mathrm{O}_{2}$ ), minute ventilation $(\dot{\mathrm{V} E})$, and respiratory exchange ratio (RER) were measured continuously during the submaximal test, however only the mean of the final 5 minutes of the test was used for analysis to ensure steady state measures. Face masks (Hans Rudolph, Kansas City, MO, USA) with small dead spaces (approximately $70 \mathrm{~mL}$ ) were fitted to participants allowing simultaneous breathing at the mouth and nose. Subjects performed a 10-minute, self-selected warm-up before the test followed by a 5-minute self-selected warm-down.

\section{Ongoing monitoring}

All of the subjects were monitored daily for morning heart rate, body weight, oxygen saturation and subjective perception of fatigue, muscle soreness, sleep, stress and training performance. The Lake Louise Acute Mountain Sickness Score and training intensity and volume were recorded throughout the camp.

\section{Training}

Training loads were calculated via the training impulse (TRIMP) method [24], which was expressed as product of stress (duration of activity) and strain (a 5-point Likert-type scale based on exercise heart rate; easy $=1$, steady $=2$, moderately $\operatorname{hard}=3$, hard $=4$, very hard=5). The heart rate training zones were identified initially from laboratory based cycling and running lactate tests, and confirmed or adjusted by training sessions performed in the field prior to the altitude training camp. The following training zones were established; easy, corresponded to heart rates where lactate was $\leq$ resting lactate 
concentration, steady=heart rate at the first lactate turn point, moderately hard=heart rate range between the first and second lactate turn point, hard=heart rates that matched the second lactate turn point $\left(\sim 4 \mathrm{mmol} . \mathrm{L}^{-1}\right)$ and very hard=heart rate from the second lactate turn point to maximum heart rate.

\section{Data analysis}

All data are means and standard deviations (SD) within and between groups and subjects. We used the baseline data as a covariate in the analysis to adjust for any differences between groups at baseline. We used a contemporary statistical approach because small performance changes can be beneficial for elite athletes [25], whereas conventional statistics can be less sensitive to such small but worthwhile changes. Specifically, we used magnitude-based inferences about effect sizes, and then to make inferences about true (population) values of the effect, the uncertainty in the effect was expressed as $90 \%$ confidence limits (CL). The probability that the true value of the effect was practically negative, trivial, or positive accounted for the observed difference, and typical error of measurement [26]. The natural logarithm of each measure was analysed to reduce any effects from non-uniformity errors and then back-transformed. For the physiological variables, the value was determined by multiplying the baseline between-subject standard deviation by Cohen's value of the smallest worthwhile effect of 0.2 [27]. The unequal variances $t$ statistic was used to analyse differences in the mean change between groups. The difference in the proportion of responders taking iron supplementation and having Acute Mountain Sickness were analysed using the general linear modelling procedure (Proc Genmod version 8.2, SAS Institute Inc., Cary, N.C.) and given as relative risk. The smallest worthwhile change in 800 -m performance was assumed to be a reduction or increase in performance time of more than $1.0 \%$, based on previous research into elite athletes competitive performance [23].

\section{Results}

Based on any improvement (change) in the sea level $800-\mathrm{m}$, swim time trial, all of the subjects were retrospectively grouped as responders and non-responders (Figure 1). Responders' performance improved by $3.2 \pm 2.2 \%$, mean \pm SD and non-responders performance decreased by $1.8 \pm 1.2 \%$, therefore compared to non-responders, the responders improved performance on average by $5.0 \%$ (90\% CL \pm $2.2 \%)$ as a result of the 20 -day altitude training camp.

\section{Physiological variables}

Heart rate and $\mathrm{SpO}_{2}$ : Compared to non-responders, responders heart rate at the end of the 5 and 10 minute periods of the submaximal cycle test as a result of the altitude camp were lower $(-3.8 \pm 4.4 \%$ and $-6.3 \pm 7.8 \%$, mean $\pm 90 \% \mathrm{CL}$, respectively). Relative to the nonresponders, the responders also showed a substantial increase in $\mathrm{SpO}_{2}$ at the start ( 0 minute $2.1 \pm 1.7$, mean $\pm 90 \% \mathrm{CL}$ ) and at the end of the 10 minute submaximal cycle test $(1.2 \pm 1.3 \%)$. Responders $\mathrm{SpO}_{2}$ at the end of the $5^{\text {th }}$ minute of the cycle was elevated compared to nonresponders but was not substantially different (Table 2). Compared to the responders, the non-responders had substantially higher $\mathrm{V} E$ and $\dot{\mathrm{V}} \mathrm{E} / \mathrm{V} \mathrm{O}_{2}$ (ventilatory equivalent) measures during the submaximal test on day 1 of the altitude training camp, and a substantially higher RER during the submaximal test on day 20 of the camp (Table 3). As a result of the 20-day altitude training camp, the economy (i.e. power (Watts) per litre of oxygen consumed) of the non-responders compared to the responders deteriorated (i.e. non-responders required more oxygen per watt of work completed). Compared to

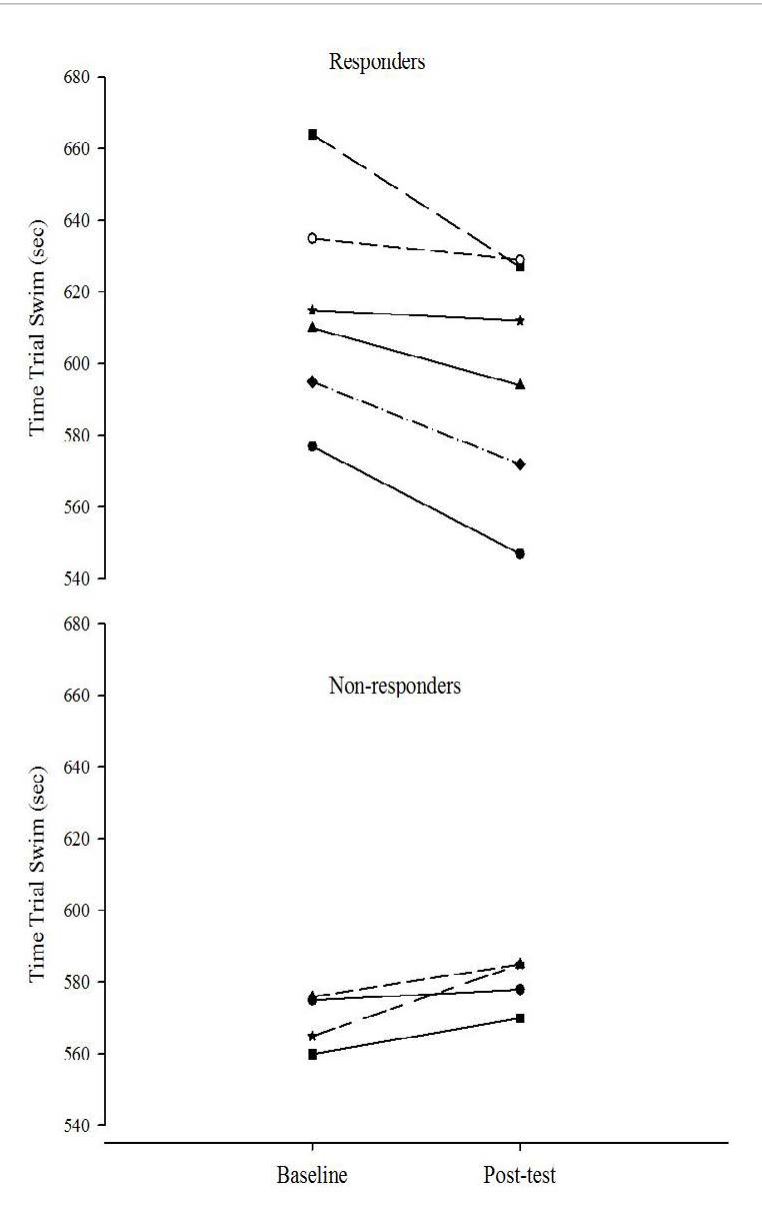

Figure 1: Individual data for $800-\mathrm{m}$ swimming time trial (sec) in the responders and non-responders 1 week before (baseline) and 1 week after (post-test) altitude camp.

non-responders, responders showed overall improvement $\mathrm{SpO}_{2}$ per wattage during the 10 minute submaximal cycle test (responders 3.6 $\pm 1.5 \%$ and non-responders $1.4 \pm 1.2 \%$ mean $\pm \mathrm{SD}$ ).

Iron supplementation: Interestingly, 4 of the 6 responders who improved their swimming performance were taking iron tablets during the altitude camp while 1 of the 4 non-responders were taking iron. In other words, those participants that underwent iron supplementation were 4.0 times $(90 \% \mathrm{CL}=1.3-12.8)$ more likely to improve performance than participants who did not take the supplement.

\section{Subjective variables}

Compared to non-responders, responders were more likely to have a lower RPE score before $(0 \mathrm{~min}$ ) and after (end of $5 \mathrm{~min}$ recovery) the 10-min submaximal cycle tests (Table 3). Changes to RPE score during the 10-min cycle test were unclear.

There were substantial differences in morning $\mathrm{SpO}_{2}$ at day 1,2 and 3 between responders and non-responders $(1.1 \pm 2.0 \%, 1.0 \pm$ $1.1 \%$ and $0.8 \pm 0.8 \%$, mean $\pm 90 \%$ CL, respectively). The morning heart rates were not substantially different between groups. The body weights in non-responders tended to decline from day 1 to day 6 (no substantial difference from day 1) of altitude camp, and then plateau. Compared to responders, non-responders body weights were 
Citation: Hamlin MJ, Manimmanakorn A, Creasy RH, Manimmanakorn N (2015) Live High-Train Low Altitude Training: Responders and Non-Responders. J Athl Enhancement 4:2.

Table 2: Mean changes in physiological measures during a 10-min submaximal cycle test (day 20 minus day 1) and chances that the differences represent real changes.

\begin{tabular}{|c|c|c|c|c|c|}
\hline & \multicolumn{2}{|c|}{ Mean Changes (\%) } & \multirow[b]{2}{*}{ Difference $; \mathrm{b} \pm 90 \% \mathrm{CL}$} & \multicolumn{2}{|c|}{ Chances that true differences are substantial ${ }^{a}$} \\
\hline & $\begin{array}{l}\text { Responders } \\
(n=6)\end{array}$ & $\begin{array}{l}\text { Non-Responders } \\
(\mathrm{n}=4)\end{array}$ & & $\%$ & Qualitative inference \\
\hline Body weight & $1.3 \pm 0.6$ & $0.3 \pm 2.9$ & 1.96 .4 & 42 & Unclear \\
\hline $\mathrm{HR} 0 \mathrm{~min}$ & $4.8 \pm 6.6$ & $10.3 \pm 14.7$ & -6.818 .3 & 68 & Unclear \\
\hline HR 5 min & $-4.7 \pm 3.9$ & $-1.0 \pm 10.6$ & $-3.8 \pm 4.4$ & 86 & Likely \\
\hline $\mathrm{HR} 10 \mathrm{~min}$ & $-2.5 \pm 8.5$ & $3.3 \pm 12.6$ & $-6.3 \pm 7.8$ & 87 & Likely \\
\hline $\mathrm{SpO}_{2} 0 \mathrm{~min}$ & $1.5 \pm 2.8$ & $-0.8 \pm 2.0$ & 2.11 .7 & 95 & Very likely \\
\hline $\mathrm{SpO}_{2} 10 \mathrm{~min}$ & $3.3 \pm 1.5$ & $2.3 \pm 0.5$ & 1.21 .3 & 83 & Likely \\
\hline
\end{tabular}

Data are mean \pm SD. Day 1 of altitude training, Day 20 of altitude training; HR 0 min, heart rate after 5 min warm up prior to 10 -min submaximal cycle test; HR $5 \mathrm{~min}$, heart rate at $5^{\text {th }}$ min during the 10 -min submaximal cycle test; $\mathrm{HR} 10 \mathrm{~min}$, heart rate during last minute of 10 -min submaximal cycle test; SpO 2 min, arterial oxyhemoglobin saturation after 5 min warm up prior to 10 -min submaximal cycle test; $\mathrm{SpO} 5$ min, arterial oxyhemoglobin saturation at $5^{\text {th }}$ min during the 10 -min submaximal cycle test; $\mathrm{SpO}_{2} 10 \mathrm{~min}$, arterial oxyhemoglobin saturation during last minute of 10 -min submaximal cycle test. ${ }^{\text {aB }}$ ased on the smallest substantial change of $1.0 \%$ for all measures. $\pm 90 \% \mathrm{CL}$ : add and subtract this number to the mean effect to obtain confidence limits for the true difference. ${ }^{b}$ Differences between groups after adjustment for baseline measures in both groups.

Table 3: Mean changes in respiratory variables over the last 5 minutes of a 10-min submaximal cycle test conducted on day 1 and day 20 of altitude training.

\begin{tabular}{|c|c|c|c|c|}
\hline & \multicolumn{2}{|c|}{ Responders $(n=6)$} & \multicolumn{2}{|c|}{ Non-Responders $(n=4)$} \\
\hline & Day 1 & Day 20 & Day 1 & Day 20 \\
\hline$\dot{\mathrm{V}} \mathrm{E}\left(\mathrm{L} \cdot \mathrm{min}^{-1}\right)$ & $68.5 \pm 19.9$ & $79.6 \pm 24.3$ & $93.1 \pm 16.6^{*}$ & $95.5 \pm 30.2$ \\
\hline$\dot{\mathrm{V}} \mathrm{O}_{2}\left(\mathrm{~L} \cdot \mathrm{min}^{-1}\right)$ & $1.7 \pm 0.5$ & $2.0 \pm 0.7$ & $1.3 \pm 0.6$ & $2.6 \pm 0.7$ \\
\hline RER & $0.94 \pm 0.02$ & $0.84 \pm 0.03$ & $0.95 \pm 0.02$ & $0.87 \pm 0.04 \wedge$ \\
\hline$\dot{\mathrm{V}} \mathrm{E} / \dot{\mathrm{V}} \mathrm{O}_{2}\left(\mathrm{~L} \cdot \mathrm{L}^{-1}\right)$ & $40.2 \pm 14.1$ & $40.8 \pm 9.9$ & $76.6 \pm 38.8^{*}$ & $52.5 \pm 13.3$ \\
\hline Economy (Watt. $L^{-1}$ ) & $132.2 \pm 42.2$ & $127.3 \pm 40.7$ & $209.6 \pm 86.3^{*}$ & $94.2 \pm 17.2 \dagger$ \\
\hline
\end{tabular}

Data are mean \pm SD. *Substantially different between responders and non-responders at day 1 of training, $\wedge$ Substantially different between responders and nonresponders at day 20 of training, †Substantially different between responders and non-responders over the course of the training (day 20 minus day 1 ). Based on the smallest substantial change of 0.2 for all measures.

substantially higher at day 1,2 and $3(5.8 \pm 7.6 \mathrm{~kg}, 6.0 \pm 7.5 \mathrm{~kg}, 6.0 \pm$ 7.6, mean $\pm 90 \% \mathrm{CL}$ ) of camp (Figure 2).

Subjective scores for fatigue, muscle soreness, the Lake Louise Acute Mountain Sickness (LL-AMS) score and training performance are presented in Figure 3. The scores for fatigue and muscle soreness in non-responders showed mostly higher scores from day 1 to day 20 compared to responders during the camp. For the LL-AMS, non-responders were 3.0 times $(90 \% \mathrm{CL}=0.5-16.6)$ more likely to suffer symptoms of AMS during first 5 days of altitude compared to responders. Specifically, at day 3 and 5, the mean AMS score in responders and non-responders were substantially different $(2.3 \pm 2.2$, $1.2 \pm 1.8$, mean $\pm 90 \% \mathrm{CL}$ ). Compared to non-responders, responders also indicated training performance was better particularly at day 2,10 and $15(0.8 \pm 1.0,0.5 \pm 0.6$ and $0.8 \pm 0.6$, mean $\pm 90 \% \mathrm{CL}$, respectively).

\section{Discussion}

This study had two main findings. First, in response to the 20-day camp utilizing a LHTL protocol, responders had a substantially higher exercise $\mathrm{SpO}_{2}$ and lower exercise $\mathrm{HR}$ during a submaximal cycle test at altitude. Second, based on the Lake Louise Acute Mountain Sickness Score and the subjective perception scores of fatigue and muscle soreness during altitude training, it seems that responders coped with the LHTL protocol stress better than non-responders. An unexpected but potentially clinically useful finding was that nonresponders had consistently higher submaximal exercise RPE scores compared to responders (Table 4).

It is obvious from our results that the LHTL strategy is not effective for all athletes trying to improve sea-level performance. The mechanisms that contribute to individual variability in responders and non-responders are difficult to elucidate. Large interindividual variations in physiological responses to hypoxia have been reported, including, erythropoietin release [7] and maximum oxygen consumption [5]. Previous research has suggested a possible reason for performance variation with altitude training may be differences in gene expression $[11,13]$ and may also relate to different stress thresholds within athletes [14]. Such variation may create an environment where some athletes might find the demand of coping with altitude in addition to normal training too stressful and maladaption may ensue, while others may thrive, giving rise to the performance variation observed.

\section{Physiological variables}

Our study, found responders showed a substantial improvement in $\mathrm{SpO}_{2}$ at $0 \mathrm{~min}$ (or just prior to the test after $5 \mathrm{~min}$ standardised warm up) and in the last minute of submaximal cycle test compared to non-responders. In fact, during the submaximal cycle test, all athletes decreased their $\mathrm{SpO}_{2}$ to varying degrees which underscores the individual variability in physiological variables among elite athletes. Some researchers have reported significant increases in arterial oxyheamoglobin saturation which contributed to significant improvement in exercise performance with LHTL (1800-1900 m) via supplemental oxygen [28]. Similar findings have been noted among climbers after a 21-day expedition to 6,194 m [29]. However, these two studies did not separate responders from non-responders. Chapman et al. reviewed the evidence for individual responses to LHTL training and found that athletes that desaturate more during 


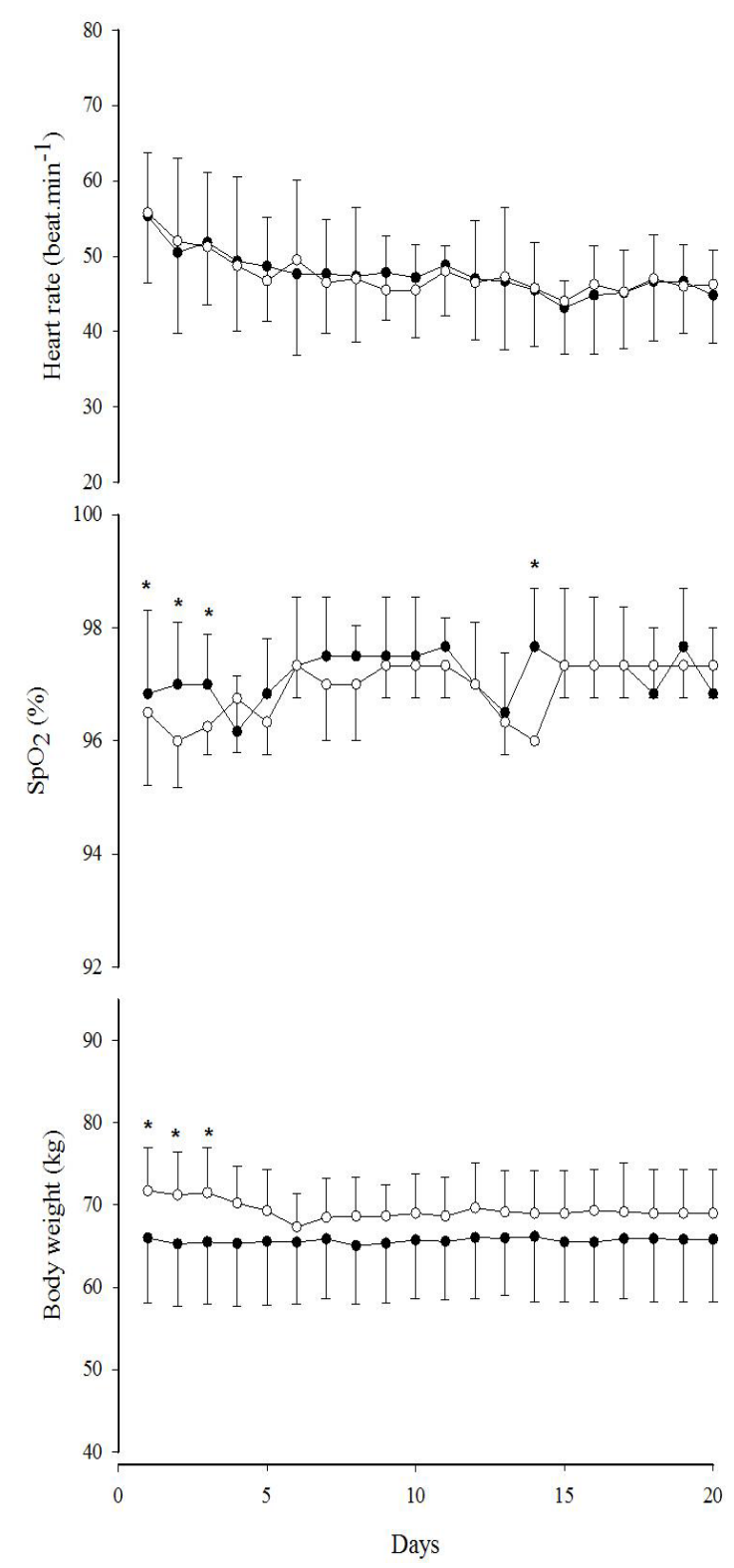

Figure 2: Daily monitoring for $\mathrm{HR}, \mathrm{SpO} 2$ and body weight throughout the altitude camp. Close circles represent responders and open circles represent non-responders. *Substantial difference from non-responders. Values are mean \pm SD.

exercise (at sea level or altitude) tend to have difficulty in adapting to altitude training while those that maintain adequate oxygen saturation respond better [6]. The relative increase (compared to non-responders) in the current study in $\mathrm{SpO}_{2}$ in responders (which corroborates the theory of Chapman et al. could be explained in part by increased haemoglobin concentration [30], enhanced erythropoietic response [7,31], which may result in increased red cell volume [4] and subsequently increased arterial oxygen content. Weil et al. noted a graded response such that an increase in red cell mass was proportional to oxyhaemoglobin saturation at sea level and altitude [32]. This may suggest a haematological aspect is involved in the beneficial adaptation to altitude. The chronic hypoxic stress facilitates increased red cell production (when adequate iron level is available) which leads to an increase haemoglobin available to carry oxygen to muscle cells (and subsequently increase $\mathrm{SpO}_{2}$ ).

Relative to non-responders, the heart rate of responders at $5 \mathrm{~min}$ and 10 min during the submaximal cycling test were substantially
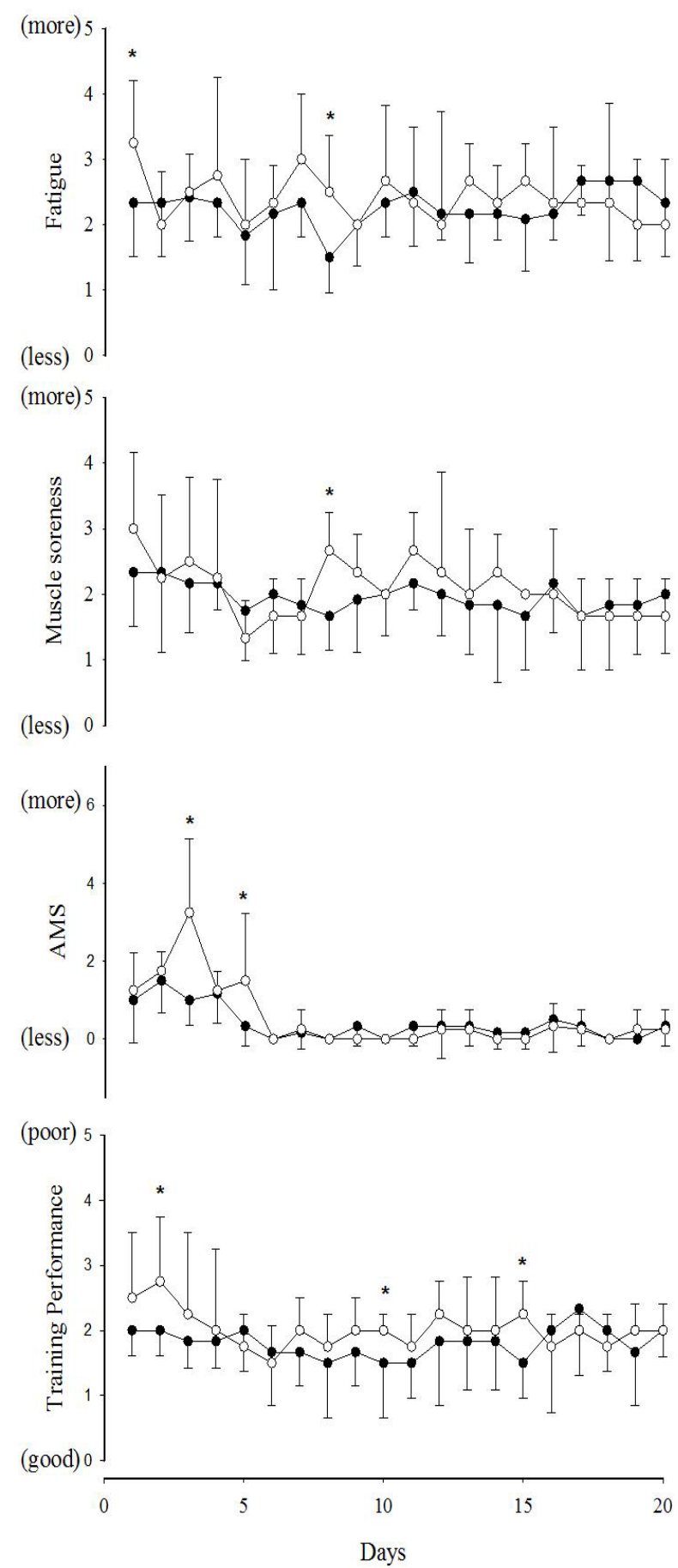

Figure 3: Subjective fatigue, muscle soreness, Lake Louise Acute Mountain Sickness and training performance score in both responders (close circles) and non-responders (open circles) throughout the altitude camp.

Note: *Substantial difference from non-responders. Values are mean $\pm \mathrm{SD}$. 
Table 4: Mean rates of perceived exertion at day 1 and day 20 in responders and non-responders before, during and after submaximal cycle test.

\begin{tabular}{|c|c|c|c|c|c|c|c|}
\hline & \multicolumn{2}{|c|}{ Responders $(n=6)$} & \multicolumn{2}{|c|}{ Non-Responders $(n=4)$} & \multirow[b]{2}{*}{$\begin{array}{l}\text { Difference; } \pm \\
90 \% \mathrm{CL}\end{array}$} & \multicolumn{2}{|c|}{ Chances that true differences are substantial ${ }^{\mathrm{a}}$} \\
\hline & Day 1 & Day 20 & Day 1 & Day 20 & & $\%$ & Qualitative inference \\
\hline RPE 0 min & $11.3 \pm 1.6$ & $12.2 \pm 1.3$ & $10.0 \pm 0.8$ & $12.5 \pm 0.6$ & $-1.4 \pm 1.3$ & 92 & Likely \\
\hline RPE 5 min & $12.8 \pm 1.6$ & $13.0 \pm 1.9$ & $11.5 \pm 1.3$ & $13.0 \pm 1.2$ & $-0.9 \pm 2.1$ & 69 & Unclear \\
\hline RPE 10 min & $13.5 \pm 2.4$ & $13.7 \pm 1.8$ & $12.8 \pm 1.0$ & $13.8 \pm 1.0$ & $-0.6 \pm 1.4$ & 57 & Unclear \\
\hline RPE cool down & $10.0 \pm 1.4$ & $8.8 \pm 1.2$ & $8.5 \pm 1.7$ & $9.5 \pm 1.3$ & $-1.6 \pm 1.2$ & 96 & Very likely \\
\hline
\end{tabular}

Data are mean \pm SD. RPE 0 min, rate of perceived exertion after 5 min warm up prior to 10 -min submaximal cycle test; RPE 5 min, rate of perceived exertion at 5 min during to 10-min submaximal cycle test; RPE $10 \mathrm{~min}$, rate of perceived exertion during last minute of 10-min submaximal cycle test; RPE cool down, rate of perceived

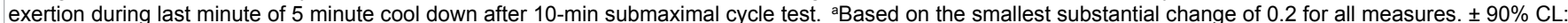
add and subtract this number to the mean effect to obtain confidence limits for the true difference.

lower. In addition, responders had lower $\dot{\mathrm{V}} \mathrm{E}, \mathrm{RER}, \dot{\mathrm{V}} \mathrm{E} / \dot{\mathrm{V}} \mathrm{O}_{2}$, but better economy (post training camp) and higher relative $\mathrm{SpO}_{2}$ to wattage ratio than non-responders. This may imply that responders have a greater ability to maintain training workload during altitude camps. These findings are consistent with the results of the Chapman et al. study, where individual variability in the response to altitude training was accounted for by maintenance of training intensity and oxygen uptake values [5]. Previous work has also found similar improvements in exercise economy after altitude training based at higher $(2500-3500 \mathrm{~m})$ and lower $(1200 \mathrm{~m})$ altitudes [22]. We suggest that the higher exercise $\mathrm{SpO}_{2}$ in responders reflects higher arterial partial pressure of oxygen. Responders are therefore able to train at higher intensities without delving into anaerobic energy systems and subsequently fatigue and therefore acquire performance improvement. The non-responders on the other hand, cannot maintain adequate oxygen levels in the blood resulting in lower $\mathrm{SpO}_{2}$ causing an increase in heart rate and $\dot{V}$ E. In addition, the lower levels of oxygen require a higher reliance on anaerobic metabolic processes, thereby elevating RER. The other possible cause for lower heart rates in responders during submaximal exercise may be due to increased vagal dominance [14], or to the elevation of red cell volume, therefore blood volume, stroke volume and ultimately cardiac output, which subsequently decreases heart rate. A recent study demonstrated that red cell volume remained elevated in responders after 2 weeks of altitude training, while non-responders red cell volume returned to their original levels [4]. However, such linkages between heart rate changes and response to altitude require further research to confirm findings.

\section{Subjective variables}

We observed that non-responders found the submaximal exercise test subjectively harder (high RPE score) than responders. Svedenhag et al. found that 2 weeks of altitude $(2000 \mathrm{~m})$ training improved RPE during exercise compared to sea-level training [33] but there are currently no studies comparing the perceived exertion of responders with non-responders. Bailey et al. also reported that 4 weeks of altitude training (1500-2000 m) improved RPE when performing a submaximal exercise test at sea-level in elite distance runners [34]. A high correlation between RPE and HR was reported by Borg et al. in a variety of work tasks (cycling and treadmill) and under varying exercise conditions (moderate to heavy intensity) [35]. It seems a major influence on RPE scores is the build-up of blood lactate and hydrogen ions due to insufficient aerobic processes to meet the demands of heavy exercise [36]. We postulate that nonresponders are required to meet the energy demands of exercise at altitude through greater anaerobic means thus pushing up RPE, heart rate and RER, however, this hypothesis is speculation as these measures were not taken in this study and further studies are required to substantiate this argument.

Acute mountain sickness (AMS) and the subjective perception score on fatigue, muscle soreness and training performance demonstrated that non-responders were not acclimatizing to the extra stress of training and hypoxia to the same extent as responders. Fatigue and muscle soreness scores indicated more stress after 24-h exposure to altitude (day 1) in non-responders compared to responders. Overall non-responders had a higher daily score on most days of the altitude training camp in all of the subjective parameters. Previous research suggested that AMS sufferers have lower resting pain thresholds and subsequently increased exercise-induced muscle soreness which was caused by free-radical-mediated skeletal muscle damage [37]. In short, low AMS and subjective perception scores of fatigue and muscle soreness could be a sign of those who adapt well to moderate altitude. It seems the responders adapt to extra stress of training at altitude whereas the non-responders find the extra stress of training and altitude too much and subsequently maladapt. Such changes in these subjective measures of participants may be useful for coaches as a detection mechanism for those athletes not coping with the altitude and training.

Reasons behind the varied performance response to LHTL training are probably multi-factorial however genetics may play a large part [38]. Studies have shown that a transcriptional factor, called a hypoxia-inducible factor (HIF), is essential in promoting cellular adaptation to changes in oxygen availability and regulating the hypoxic gene expression [39]. Under hypoxic conditions, the HIF-1a complex is stable, allowing for transcriptional activation and ultimate stimulation of proteins such as EPO [40] and vascular endothelial growth factor [41]. HIF-1 $\alpha$ also moderates other physiological responses at altitude including glucose transport and glycolytic enzyme activity [42]. Conversely, the studies of Mason et al. (2004) and (2007) showed that under low-oxygen conditions glycolysis is the central source of anaerobic energy which is regulated by HIF-1a. It can be seen in HIF-1a knockout mice that loss of HIF-1a in skeletal muscle causes an adaptive response by shifting from glycolytic metabolism toward fatty acid oxidation leading to an increased capacity for endurance exercise $[43,44]$. We speculate that the nonresponders in this study probably sensitive to the hypoxic condition consequently produced more HIF-1a compared to responders which may have increased the reliance on glycolysis and subsequently increased RER during exercise. However, more research is required in this area since other researchers have been unable to identify 
genes that can be overwhelmingly linked to the individual variability observed in responders versus non-responders [10] and HIF-1a gene expression quantification is unable to predict poor and good responder-athletes to the LHTL model [11].

From this research it seems clear that athletes who respond to altitude are less stressed in terms of lower heart rate, $\dot{\mathrm{V}} \mathrm{E}$ and higher levels of arterial oxygen saturation during submaximal exercise. Athletes that are not responding seem to perceive themselves as being more fatigued, become less efficient (use more oxygen per watt), have more muscle soreness, and higher AMS scores, particularly over the first few days of altitude. It seems the non-responders are unable to adapt to the increased demand for oxygen required by the muscles during exercise at altitude, resulting in fatigue and poor performance adaptation. Possible confounding factors behind athletes who respond to altitude training and those that do not may be their iron stores. Clearly, there is the need for further studies to investigate possible mechanisms.

A limitation of this study is lack of a sea-level control group which does not allow us to distinguish whether the observed effects are due to the altitude or to the effect of training. Indeed, altitudes that are more common for such training (e.g. 2000-2500 m) may have been better at separating out clear differences between responders and non-responders, but such altitude training bases are unavailable in New Zealand. In addition, maximal testing (run or cycle) may have provided greater evidence for differences between the groups. However, we consider our observations are worthwhile given the lack of information on such groups (elite triathletes all ranked within the world top 100). Nevertheless, these results should remain speculative until further research is conducted in a more controlled study.

\section{Conclusion}

This investigation demonstrated that changes in some simple measures taken during submaximal exercise $\left(\mathrm{SpO}_{2}, \mathrm{HR}, \mathrm{V} \mathrm{E}\right.$, economy and RPE) or at rest (perception of fatigue, muscle soreness, training performance and the acute mountain sickness score) during an altitude sojourn may be useful indicators for classifying athletes that are coping and are likely to improve subsequent sea-level performance from those that are suffering increased stress and are likely to decrease subsequent sea-level performance. These physiological indicators and subjective variables provide non-invasive screening for athletes who could profit from such hypoxic exposure.

\section{Acknowledgements}

The authors acknowledge the Lincoln University Research Fund for financial support, the New Zealand Triathlon athletes and their coaches, and the Snow Farm in Wanaka for their assistance.

\section{References}

1. Stray-Gundersen J, Chapman RF, Levine BD (2001) "Living high-training low" altitude training improves sea level performance in male and female elite runners. J Appl Physiol (1985) 91: 1113-1120.

2. Bonetti DL, Hopkins WG (2009) Sea-level exercise performance following adaptation to hypoxia: a meta-analysis. Sports Med 39: 107-127.

3. Álvarez-Herms J, Julià-Sánchez S, Hamlin MJ, Corbi F, Pagès T, et al. (2015) Popularity of hypoxic training methods for endurance-based professional and amateur athletes. Physiol Behav 143: 35-38.

4. Heinicke K, Heinicke I, Schmidt W, Wolfarth B (2005) A three-week traditional altitude training increases hemoglobin mass and red cell volume in elite biathlon athletes. Int J Sports Med 26: 350-355.

5. Chapman RF, Stray-Gundersen J, Levine BD (1998) Individual variation in response to altitude training. J Appl Physiol (1985) 85: 1448-1456.
6. Chapman RF (2013) The individual response to training and competition at altitude. Br J Sports Med 47 Suppl 1: i40-44.

7. Friedmann B, Frese F, Menold E, Kauper F, Jost J, et al. (2005) Individual variation in the erythropoietic response to altitude training in elite junior swimmers. Br J Sports Med 39: 148-153.

8. Ge RL, Witkowski S, Zhang Y, Alfrey C, Sivieri M, et al. (2002) Determinants of erythropoietin release in response to short-term hypobaric hypoxia. J Appl Physiol (1985) 92: 2361-2367

9. Simonson TS, McClain DA, Jorde LB, Prchal JT (2012) Genetic determinants of Tibetan high-altitude adaptation. Hum Genet 131: 527-533.

10. Jedlickova K, Stockton DW, Chen H, Stray-Gundersen J, Witkowski S, et al. (2003) Search for genetic determinants of individual variability of the erythropoietin response to high altitude. Blood Cells Mol Dis 31: 175-182.

11. Mounier R, Pialoux V, Cayre A, Schmitt L, Richalet JP, et al. (2006) Leukocyte's Hif-1 expression and training-induced erythropoietic response in swimmers. Med Sci Sports Exerc 38: 1410-1417.

12. Burtscher M, Szubski C, Faulhaber M (2008) Prediction of the susceptibility to AMS in simulated altitude. Sleep Breath 12: 103-108.

13. Wilber RL, Stray-Gundersen J, Levine BD (2007) Effect of hypoxic "dose" on physiological responses and sea-level performance. Med Sci Sports Exerc 39: 1590-1599.

14. Hamlin MJ, Manimmanakorn A, Sandercock GR, Ross JJ, Creasy RH, et al. (2011) Heart rate variability in responders and non-responders to livemoderate, train-low altitude training. Proceedings of the World Academy of Science Engineering and Technology: International Conference on Physical Activity and Sport Science 77: 1704-1709.

15. Ainslie PN, Kolb JC, Ide K, Poulin MJ (2003) Effects of five nights of normobaric hypoxia on the ventilatory responses to acute hypoxia and hypercapnia. Respir Physiol Neurobiol 138: 193-204.

16. Robertson EY, Saunders PU, Pyne DB, Aughey RJ, Anson JM, et al. (2010) Reproducibility of performance changes to simulated live high/train low altitude. Med Sci Sports Exerc 42: 394-401.

17. Chapman RF, Karlsen T, Resaland GK, Ge RL, Harber MP, et al. (2014) Defining the "dose" of altitude training: how high to live for optimal sea level performance enhancement. J Appl Physiol (1985) 116: 595-603.

18. Gore CJ, Hahn A, Rice A, Bourdon P, Lawrence S, et al. (1998) Altitude training at $2690 \mathrm{~m}$ does not increase total haemoglobin mass or sea level VO2max in world champion track cyclists. J Sci Med Sport 1: 156-170.

19. Gore CJ, Clark SA, Saunders PU (2007) Nonhematological mechanisms of improved sea-level performance after hypoxic exposure. Med Sci Sports Exerc 39: 1600-1609.

20. Gore CJ, Hopkins WG (2005) Counterpoint: positive effects of intermittent hypoxia (live high:train low) on exercise performance are not mediated primarily by augmented red cell volume. J Appl Physiol (1985) 99: 2055-2057.

21. Roels B, Hellard $P$, Schmitt $L$, Robach $P$, Richalet JP, et al. (2006) Is it more effective for highly trained swimmers to live and train at $1200 \mathrm{~m}$ than at 1850 $\mathrm{m}$ in terms of performance and haematological benefits? $\mathrm{Br} \mathrm{J}$ Sports Med 40: e4.

22. Schmitt L, Millet G, Robach P, Nicolet G, Brugniaux JV, et al. (2006) Influence of "living high-training low" on aerobic performance and economy of work in elite athletes. Eur J Appl Physiol 97: 627-636.

23. Paton CD, Hopkins WG (2005) Competitive performance of elite Olympicdistance triathletes: reliability and smallest worthwhile enhancement Sportscience 9: 1-5

24. Banister EW, Calvert TW (1980) Planning for future performance: implications for long term training. Can J Appl Sport Sci 5: 170-176.

25. Hopkins WG, Hawley JA, Burke LM (1999) Design and analysis of research on sport performance enhancement. Med Sci Sports Exerc 31: 472-485.

26. Batterham AM, Hopkins WG (2006) Making meaningful inferences about magnitudes. Int J Sports Physiol Perform 1: 50-57.

27. Cohen J (1988) Statistical power analysis for the behavioral sciences. $\left(2^{\text {nd }}\right.$ edtn), Lawrence Erlbaum, New Jersey. 
Citation: Hamlin MJ, Manimmanakorn A, Creasy RH, Manimmanakorn N (2015) Live High-Train Low Altitude Training: Responders and Non-Responders. J Athl Enhancement 4:2.

28. Wilber RL, Holm PL, Morris DM, Dallam GM, Callan SD (2003) Effect of $\mathrm{F}(\mathrm{I}) \mathrm{O}(2)$ on physiological responses and cycling performance at moderate altitude. Med Sci Sports Exerc 35: 1153-1159.

29. Green H, Roy B, Grant S, Burnett M, Tupling R, et al. (2000) Downregulation in muscle $\mathrm{Na}(+)-\mathrm{K}(+)$-ATPase following a 21-day expedition to $6,194 \mathrm{~m}$. J Appl Physiol (1985) 88: 634-640.

30. Savourey G, Garcia N, Besnard Y, Guinet A, Hanniquet AM, et al. (1996) Preadaptation, adaptation and de-adaptation to high altitude in humans: cardioventilatory and haematological changes. Eur J Appl Physiol Occup Physio 73: 529-535.

31. Hamlin MJ, Hellemans J (2004) Effects of intermittent normobaric hypoxia on blood parameters in multi-sport endurance athletes. Med Sci Sports Exerc 36: S337.

32. Weil JV, Jamieson G, Brown DW, Grover RF (1968) The red cell massarterial oxygen relationship in normal man. Application to patients with chronic obstructive airway disease. J Clin Invest 47: 1627-1639.

33. Svedenhag J, Saltin B, Johansson C, Kaiijser L (1991) Aerobic and anaerobic exercise capacities of elite middle-distance runners after training at moderate altitude. Scand J Med Sci Sports 1: 205-215

34. Bailey DM, Davies B, Romer L, Castell L, Newsholme E, et al. (1998) Implications of moderate altitude training for sea-level endurance in elite distance runners. Eur J Appl Physiol Occup Physiol 78: 360-368.

35. Borg GA, Noble BJ (1974) Perceived exertion. Exerc Sports Sci Rev 2: 131 154
36. O'Sullivan SB (1984) Perceived exertion. A review. Phys Ther 64: 343-346.

37. Bailey DM, Davies B, Young IS, Hullin DA, Seddon PS (2001) A potential role for free radical-mediated skeletal muscle soreness in the pathophysiology of acute mountain sickness. Aviat Space Environ Med 72: 513-521.

38. Scoggin CH, Doekel RD, Kryger MH, Zwillich CW, Weil JV (1978) Familia aspects of decreased hypoxic drive in endurance athletes. J Appl Physiol Respir Environ Exerc Physiol 44: 464-468.

39. Gunga HC, Kirsch KA, Roecker L, Kohlberg E, Tiedemann J, et al. (2007) Erythropoietin regulations in humans under different environmental and experimental conditions. Respir Physiol Neurobiol 158: 287-297.

40. Caro J (2001) Hypoxia regulation of gene transcription. High Alt Med Biol 2 : 145-154.

41. Wang GL, Semenza GL (1996) Molecular basis of hypoxia-induced erythropoietin expression. Curr Opin Hematol 3: 156-162.

42. Clerici C, Matthay MA (2000) Hypoxia regulates gene expression of alveolar epithelial transport proteins. J Appl Physiol (1985) 88: 1890-1896.

43. Mason SD, Howlett RA, Kim MJ, Olfert IM, Hogan MC, et al. (2004) Loss of skeletal muscle HIF-1alpha results in altered exercise endurance. PLoS Bio 2: e288.

44. Mason SD, Rundqvist H, Papandreou I, Duh R, McNulty WJ, et al. (2007) HIF-1alpha in endurance training: suppression of oxidative metabolism. Am J Physiol Regul Integr Comp Physiol 293: R2059-2069.

\section{Author Affiliation}

${ }^{1}$ Department of Tourism, Sport and Society, Lincoln University, New Zealand ${ }^{2}$ Department of Physiology, Faculty of Medicine, Khon Kaen University, Khon Kaen 40002, Thailand

${ }^{3}$ High Performance Sports Physiologist, Triathlon, New Zealand

${ }^{4}$ Department of Rehabilitation, Faculty of Medicine, Khon Kaen University, Khon Kaen 40002, Thailand

Submit your next manuscript and get advantages of SciTechnol submissions

* 50 Journals

* 21 Day rapid review process

* 1000 Editorial team

* 2 Million readers

* Publication immediately after acceptance

* Quality and quick editorial, review processing

Submit your next manuscript at $\bullet$ www.scitechnol.com/submission 